\title{
Serum immunoglobulins to endotoxin core glycolipid: establishment of normal concentrations
}

\author{
S K Jackson, J Parton, G Shortland, J M Stark, E N Thompson
}

\begin{abstract}
Serum antibody to lipopolysaccharide core glycolipid was measured in normal children and in full term and premature $(\leqslant 1500 \mathrm{~g})$ infants. Antilipopolysaccharide core glycolipid antibody was present in term infants and normal children, and reached adult titres by 15 years of age. The specific anti core glycolipid antibody was predominately of the IgG class. Preterm infants ( $<32$ weeks' gestation) had significantly lower titres of antilipopolysaccharide core glycolipid than more mature preterm or term infants. The results suggest that administration of anticore glycolipid immunoglobulin may be beneficial in the treatment or prevention of Gram negative septicaemia in preterm and very young infants.
\end{abstract}

Despite improvements in antibiotic treatment, infections, often due to Gram negative organisms, remain a major problem in newborn infants, especially those of low birth weight and in children who are immune compromised or receiving intensive care.

Antibody deficiency may contribute crucially to the increased susceptibility to infection. ${ }^{1}$ Preterm infants have low concentrations of IgG because maternal transfer of antibody is greatest in the last six weeks of gestation. ${ }^{2}$ Any delay in maturation of their own antibody system would exacerbate the situation. These observations have led to the suggestion that prophylactic administration of immunoglobulin may be of therapeutic benefit in 'high risk' groups.

Many of the toxic manifestations induced by Gram negative bacterial infections are believed to be mediated by the lipopolysaccharide (endotoxin) component of the outer membrane of these bacteria. Antibiotics are unable to prevent the toxic effects of lipopolysaccharide and may even promote the release of lipopolysaccharide from bacteria. ${ }^{3}$

Antibody directed against the core glycolipid, the central part of the lipopolysaccharide, may cross react with other Gram negative bacteria because many determinants of the core glycolipid are shared.

In this study we have measured antibody to core glycolipid in sera from children, term and preterm infants and mothers, to determine the titres in a normal population.

\section{Subjects and methods}

Samples were obtained from newborn infants and children aged 1 month to 15 years. The newborn infants included 26 preterm (28-36 weeks' gestation) and 53 full term infants. In 36 of them paired samples were obtained: cord blood from the infant and mother's blood within 48 hours of the birth. In none of the children or mothers were there signs of infection at the time of collection or before delivery. Three were born by caesarean section. Ninety four other children older than 4 weeks were studied (mean (SD) age $6 \cdot 18(5 \cdot 6)$ years). Most were routine outpatient attenders for noninfective conditions and children admitted for elective surgery. None was on drugs except carbamazepine $(n=4)$ and sodium valproate $(n=2)$. No child had samples taken specifically for these studies. The blood was separated immediately and stored at $-70^{\circ} \mathrm{C}$ until tested.

\section{ENZYME LINKED IMMUNOADSORBENT ASSAY}

(ELISA) FOR IGG AND IGM TO ENDOTOXIN CORE GLYCOLIPID

Lipopolysaccharide core glycolipid coated microtitre plates were kindly donated by Dr G R Barclay, Scottish Blood Transfusion Centre, Edinburgh. The plates had been coated with a 'cocktail' of core lipopolysaccharide from rough mutants of each of Escherichia coli, Salmonella typhimurium, Pseudomonas aeruginosa, and Klebsiella aerogenes. Plates were post coated with $5 \%$ bovine serum albumin to block remaining antibody binding sites.

Serum samples were diluted $1 / 200$ in phosphate buffered saline of $\mathrm{pH} 7 \cdot 2$ containing $0 \cdot 1 \%$ (v/v) Tween-20, 0.05\% (w/v) sodium azide, 4\% (w/v) polyethylene glycol (PEG-6000), and 2\% $(\mathrm{w} / \mathrm{v})$ bovine serum albumin. Sterile pyrogen free water was used throughout. Diluted serum samples were added in duplicate $(100 \mu \mathrm{l})$ to adjacent wells along the rows of the microtitre plate.

The last row of the plate contained control serum at a range of dilutions from $1 / 25$ to $1 / 3400$. Serum from a single human volunteer was used as the positive control and all results were expressed as a percentage of this control. In addition medium titre and negative sera were used as quality controls.

Plates were developed with either antihuman IgG or IgM conjugated alkaline phosphatase, and after substrate addition the final colour was read in a Titertek Multiscan ELISA plate reader at $405 \mathrm{~nm}$. Standard curves and test sera results were automatically computed on an Epson PCE microcomputer.

Results

Antibody titres to lipopolysaccharide core 
Antiendotoxin core glycolipid antibody and total immunoglobulins as a function of age in neonates and normal children. Results are given as mean (2SD) of logged values

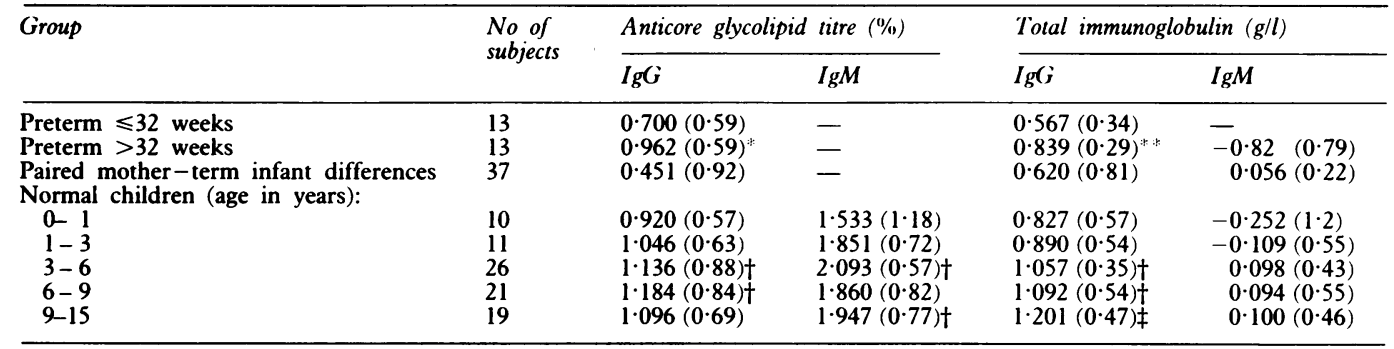

${ }^{*} \mathrm{p}<0.05 v \leqslant 32$ weeks; ${ }^{* *} \mathrm{p}<0.005 v \leqslant 32$ weeks; $\mathrm{tp}<0.05 v 0-1$ years; $\neq \mathrm{p}<0.005 v 0-1$ years.

glycolipid and total IgG and IgM concentrations are presented in the table. This shows that infants of less than 32 weeks' gestation have significantly $(p<0.05)$ less antilipopolysaccharide core glycolipid antibody than infants of greater than 32 weeks' gestation. The antibody titres to this antigen in cord sera from full term infants were equal to or slightly in excess of those in the corresponding maternal sera.

IgG and IgM antibody titres to lipopolysaccharide core glycolipid in normal children aged between 6 months and 15 years show a significant age related increase in antibody to this antigen. IgM titres were higher and more widely spread than IgG.

The total immunoglobulins (IgG and IgM) for normal children, premature infants, full term infants, and maternal sera showed similar age related trends and compared well with values reported in the literature. ${ }^{4}$

\section{Discussion}

Human serum antibody to lipopolysaccharide core glycolipid was detected in normal children showing an age related increase, reaching adult titres by 15 years of age (table). The IgM titres were higher and more widely spread than IgG, probably a reflection of nonspecific cross reacting IgM antibody. This suggests that specific antibody to lipopolysaccharide core glycolipid is predominantly IgG; this is in agreement with other observers. ${ }^{5}$

As specific antibodies to lipopolysaccharide core glycolipid are found in the IgG class, there will be maternal transfer to the fetus across the placenta. We detected IgG antilipopolysaccharide core glycolipid antibody in full term infants and preterm infants over 32 weeks' gestation. The titres in these groups were equal to or slightly in excess of the maternal values, reflecting the addition of fetally produced IgG to the immunoglobulins that have crossed the placenta. ${ }^{6}$ IgM antibody does not cross the placenta and could not be detected in full term or preterm infants. Transfer of IgG antibody to the fetus may help protect the newborn against Gram negative bacteria ${ }^{7}$; the specific antibody detected in the present observations may also protect against endotoxaemia.

Preterm infants of less than 32 weeks' gestation were shown to have significantly lower titres of antilipopolysaccharide core glycolipid antibody than more mature preterm or full term infants.
Most maternal transfer of antibody to the fetus takes place in the last six weeks of pregnancy, so that such premature infants may be considered immune compromised. ${ }^{8}$

Septicaemia is an important cause of mortality and morbidity in the newborn period. The incidence varies from one to 10 per thousand births ${ }^{9}$ and is commoner in preterm infants. Although the prevalence of infections with Gram positive bacteria is increasing, ${ }^{10}$ possibly related to invasive procedures and centrally placed catheters, ${ }^{11}$ Gram negative infections are nevertheless an important cause of morbidity and mortality. ${ }^{12}$

Neonatal defence mechanisms against bacterial infections may be impaired for a number of reasons, including immunoglobulin deficiency. ${ }^{4}$ This has prompted studies into the use of immunoglobulin treatment for prophylaxis of infections in premature infants. ${ }^{6}{ }^{7}$ Intramuscular injections of human antilipopolysaccharide antisera have been used in low birthweight babies suffering from septicaemia, ${ }^{13}$ although a beneficial effect was not demonstrated. This may have been due to the disadvantages of intramuscularly administered antisera. ${ }^{14}$ Furthermore, natural titres of antibody before or after treatment were not determined in these studies.

The development of gammaglobulin that is safe and effective for intravenous use has stimulated interest into the possible prophylactic use of specific antiendotoxin antibody.

Numerous studies have suggested a beneficial role for antiendotoxin immunoglobulin in the treatment and prophylaxis of Gram negative septicaemia. ${ }^{15}$ The cocktail of core glycolipids used in the present study is particularly useful as it represents common antigenic determinants. Antibodies to the core glycolipid should, therefore, be cross reactive with endotoxin from heterologous organisms. ${ }^{16}$

A knowledge of normal antibody titres is essential for the proper assessment of immunotherapy for the treatment or prevention of septicaemia. This study has established the normal titres of anticore glycolipid antibody in preterm and full term infants and older children, and suggests that administration of anticore glycolipid immunoglobulin may be beneficial in the treatment or prevention of Gram negative septicaemia in preterm and very young infants.

We thank the nursing staff at the maternity unit, St David's Hospital, Cardiff, for their help and cooperation in the collection of samples during this study. 
1 Bernbaum J, Anolik R, Polin RA, Douglas SD. Development of the premature infant's host defence system and its relationship to routine immunizations. Clin Perinatol 1984; 11:73-8.

2 Hobbs JR, Davis JA. Serum-G-globulin levels and gestational age in premature babies. Lancet $1967 ; \mathbf{i}: 751-9$.

3 Shenep JC, Mogan KA. Kinetics of endotoxin release during antibiotic therapy for experimental gram-negative bacterial sepsis. F Infect Dis 1984;150:380-8.

4 Ballour M, Cates KL, Rowe JC, et al. Development of the immune system in very low birthweight premature infants: concentrations of plasma immunoglobulins and patterns of infections. Pediatr Res 1986;20:899-904.

5 Izui S, Eisenberg RA, Dixon FJ. Subclass restricted IgG polyclonal antibody production in mice injected with lipid polyclonal antibody production in mice injected with lipid
A-rich lipopolysaccharides. $\mathcal{F}$ Exp Med 1981;153:324-8.

6 Yoder MC, Polin RA. Immunotherapy of neonatal septicaemia. Pediatr Clin North Am 1986;33:481-501.

7 Baley JE. Neonatal sepsis: the potential for immunotherapy. Clin Perinatol 1988;15:755-71.

8 Pilgrim U, Fontanellaz HP, Hitzig WH, Evers G. Norma values of immunoglobulins in premature and in full-time infants, calculated as percentiles. Helv Paediatr Acto 1975;30:121-4.
9 Freedman RM, Ingram DL, Gross I, et al. A half-century of sepsis at Yale. Am $\mathcal{F}$ Dis Child 1981;135:140-4.

10 Bennet $R$, Eriksson $M$, Zetterstrom $R$. Increasing incidence of neonatal septicaemia: causative organisms and predisposing risk factors. Acta Paediatr Scand 1981;70:207-10.

11 Placzek MM, Whitelaw A. Early and late neonatal septicaemia. Arch Dis Child 1983;58:728-31.

12 Bortolussi $R$. Potential for intravenous gammaglobulin use in neonatal gram-negative infection: an overview. Pediat Infect Dis 1986;5:S198-200.

13 Steen JA. Gammaglobulin in preventing infections in prematures. Archives of Paediatrics 1960;77:291-4.

14 Dwyer JM. Thirty years of supplying the missing link: history of gammaglobulin therapy for immunodeficient history of gammaglobulin therapy

15 Ziegler EJ, McCutchan JA, Fierer J, et al. Treatment of gram-negative bacteraemia and shock with human antiserum to a mutant Escherichia coli. $N$ Engl $f$ Med serum to a mutant

16 Barclay GR, Scott BB. Serological relationships between Escherichia coli and salmonella smooth and rough-mutant lipopolysaccharides as revealed by enzyme-linked immunosorbent assay for human immunoglobulin $\mathrm{G}$ antiendotoxin antibodies. Infect Immun 1987;55:2706-14. 